\title{
Attitudes and behaviours of top-level junior rugby union coaches towards the coaching of proper contact technique in the tackle - a pilot study
}

\author{
S Hendricks, M Sarembock \\ MRC/UCT Research Unit for Exercise Science and Sports Medicine, Department of Human Biology, Faculty of Health Sciences, University of Cape Town, \\ Cape Town, South Africa \\ S Hendricks, $\mathrm{PhD}$
}

Department of Health and Rehabilitation Sciences, Division of Physiotherapy, Faculty of Health Sciences, University of Cape Town, Cape Town, South Africa M Sarembock, BSc (Physiotherapy)

Corresponding author: S Hendricks (sharief.hendricks01@gmail.com)

Background. Coaching strategies for effective technique and injury prevention have been proposed for the tackle. Despite this, little is known about current coaching attitudes and the behaviours of coaches towards proper contact technique in the tackle, especially at the junior level.

Objective. To report on the attitudes and behaviours of junior rugby union coaches towards coaching of proper contact technique in the tackle.

Methods. Seven coaches of the top 8 rugby-playing schools (Premier Division) in the Western Province Rugby Union participated in the study (representing $88 \%$ of the entire population of top-level junior coaches in the region). Coaches completed a questionnaire, modelled on previous research, surveying attitudes and behaviours towards tackling.

Results. Proper technique for injury prevention was rated as very important (57\%) and important (29\%), with $14 \%$ undecided. Proper technique to improve performance was rated as very important (57\%) and important (43\%). To further develop coaching knowledge and to develop new training methods, 'coaching colleagues' (very much - 71\%; mean rating 4.7; 95\% CI 4.3 - 5.2) was rated as the most often used.

Conclusion. Collectively, the coaches in this study demonstrated a positive attitude towards injury prevention and performance. Additional means of communicating information to coaches, other than the traditional channels, have also been highlighted here.

S Afr J SM 2013;25(1):8-11. DOI:10.7196/SAJSM.459

The tackle is an important component of rugby union. The ability of a player to engage and tolerate frequent contact in the tackle, whether as a ball-carrier or tackler, influences the performance of the team and exposes players to a high risk of injury. Therefore, in part, for safe and successful participation in rugby union, coaching of tackle contact techniques is essential. ${ }^{[1,2]}$

The knowledge, attitude and behaviour of coaches have been highlighted as key instruments in the implementation of injuryprevention strategies in junior sports. ${ }^{[3,4]}$ In view of this, researchers have studied coaches' knowledge, attitudes and behaviours to understand the context in which to translate evidence-based injuryprevention training programmes. ${ }^{[2,5-8]}$ For example, Premier Division coaches in the Australian Football League generally ranked injury prevention lower than the needs of general training sessions and team performance. ${ }^{[8]}$ A sample of junior rugby union coaches had limited knowledge of injury mechanisms and injury management. ${ }^{[2]}$ The same sample of coaches identified the tackle as the facet of play where most injuries occur, but at the same time, the perception of increasing technical knowledge for ball-carrying contact techniques and tackling techniques was reported less frequently. ${ }^{[2]}$

For reasons mentioned earlier, the tackle in rugby union has received much attention in the literature recently, with coaching strategies for effective technique and injury prevention being proposed ${ }^{[1]}$ Despite this, very little has been documented on the current coaching attitudes and behaviours of coaches towards proper contact technique in the tackle, especially at the junior level. Therefore, the purpose of this study was to report on the attitudes and behaviours of junior rugby union coaches towards the coaching of proper contact technique in the tackle. It should be noted that this study acted as a pilot for a larger study, the aims of which are not only to examine self-reported data on coach attitudes and behaviour, but also to directly observe coach behaviour during training sessions.

\section{Methods}

The coaches of the top 8 rugby-playing schools (Premier Division) in the Western Province Rugby Union were approached for this study. 
Seven coaches gave informed consent to participate, representing $88 \%$ of the entire population of top-level junior coaches in the region. The University of Cape Town Research Ethics Committee approved the study, and all coaches provided informed consent before participating.

The questionnaire used in the study was modelled on previous research into the attitudes and behaviours towards tackling. ${ }^{[9]}$ The self-reported questionnaire was aimed at gaining insight into attitudes and behaviours of coaches towards the coaching of proper contact technique in the tackle, but without burdening the coach. With this in mind, the questionnaire consisted of 2 background questions (surveying the highest level coached, experience and accredited coaching qualifications), 2 attitudinal and 3 behavioural questions. All questions were closed-ended, comprised of a list of possible answers (items) and response categories, with a 5-point ordinal Likert scale represented by a numerical value. Coaches had to rate the importance and quantity of each item in the question.

Despite studying $88 \%$ of the population, the sample size $(N=7)$ was too low to conduct interpretive statistics; therefore, descriptive statistics were reported. Data were expressed as means with $95 \%$ confidence intervals (CIs) and/or as percentages of the scores on the Likert scale.

\section{Results}

\section{Coaching background information}

Mean coaching experience was 14 years (standard deviation (SD) \pm 6 ). Seventy-one per cent $(n=5)$ of the coaches had a level 2 coaching qualification and $14 \%(n=1)$ had a level 1 qualification. Twentynine per cent $(n=2)$ of the coaches had a tertiary qualification, and $29 \%$ completed an exercise-training accreditation. All coaches had completed the BokSmart training course. ${ }^{[10]}$

\section{Attitude}

Fifty-seven per cent of coaches rated proper technique to prevent injury as very important, $29 \%$ rated proper technique to prevent injury as important, and $14 \%$ were undecided on the matter. In comparison, $57 \%$ of coaches indicated proper technique to improve tackling performance as very important and the remaining $43 \%$ indicated proper technique to improve tackling performance as important.
When asked to rate the importance of proper technique for the different phases of play, $86 \%$ of coaches reported 'ball-carrying', 'rucking' and 'ball-handling' as very important (Table 1). For the same question, $71 \%$ reported 'tackling' and 'scrumming' as very important. 'Line-outs' ( $57 \%$ very important), 'mauling' ( $57 \%$ very important) and 'falling to ground' ( $43 \%$ very important) were not rated as important. When the different phases of play were ranked according to mean rating, 'ballcarrying' (4.9; 95\% CI 4.5 - 5.2), 'scrumming' (4.7; 95\% CI 4.2 - 5.2) and 'tackling' (4.7; 95\% CI 4.3 - 5.2) were ranked most important (Table 1). Proper technique for 'falling to ground' (4; 95\% CI 2.9 - 5.1) was rated as the least important phase of play.

\section{Behaviour}

To further develop coaching knowledge and to develop new training methods, 'coaching colleagues' (71\% very much; mean rating 4.7; 95\% CI 4.3 - 5.29), 'televised rugby matches' (very much - 57\%; mean rating 4.6; $95 \%$ CI 4.1 - 5.1) and 'attending live rugby matches' (57\% very much; mean rating 4.4; 95\% CI 3.9 - 4.9) were rated as the most often used, whereas 'attending workshops' (29\% a little; $29 \%$ a fair amount; mean rating 2.9; 95\% CI 1.6 - 4.1), 'attending formal coaching/physical education courses' (29\% a little; $57 \%$ a fair amount; mean rating 2.9; $95 \%$ CI 2.2 - 3.5), and 'newspapers' (43\% not at all; mean rating 2.4; 95\% CI 0.9 - 3.9) were ranked the least-often used (Table 2).

Coaching methods that included the entire team, whether as 'verbal instruction to the entire team' ( $71 \%$ very much; $21 \%$ much), 'demonstration to the entire team' ( $71 \%$ very much; $21 \%$ much), or 'identifying a team problem and coaching the team accordingly' ( $57 \%$ very much, $43 \%$ much) were used more often than focusing on individual players. Table 3 ranks the mean ratings of importance for different drills and equipment used to train the tackle. Mean ratings were ranked for (i) injury prevention, and (ii) improving performance.

\section{Discussion}

The aim of this article was to report on the attitudes and behaviours of junior top-level rugby union coaches. Seven out of the 8 top rugbyplaying schools were surveyed, representing $88 \%$ of the population. The reported importance of proper technique to lower the risk of injury or improve performance was positive as most coaches rated

Table 1. Attitudes (importance) toward proper technique during the different phases of play*

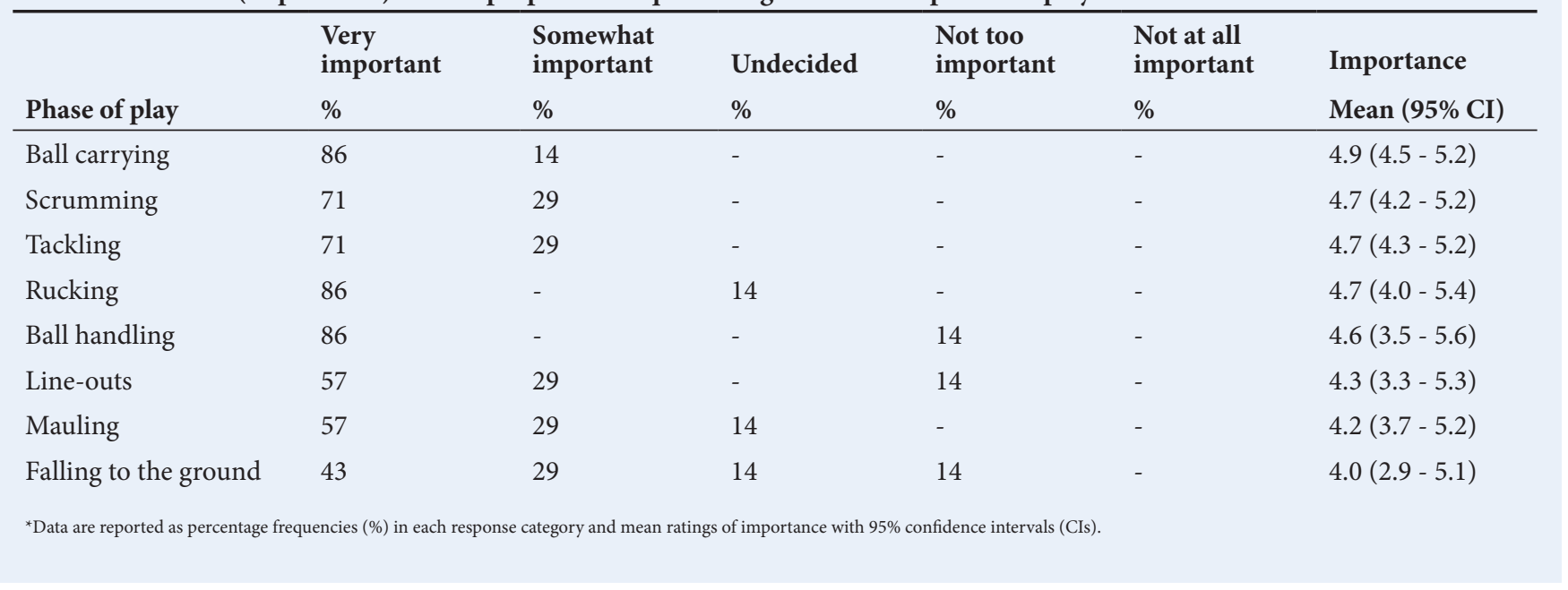


Table 2. Reported use of resources to further coaching knowledge and develop new training techniques*

\begin{tabular}{|c|c|c|c|c|c|c|}
\hline Resource & $\begin{array}{l}\text { Very much } \\
\%\end{array}$ & $\begin{array}{l}\text { Much } \\
\%\end{array}$ & $\begin{array}{l}\text { A fair amount } \\
\%\end{array}$ & $\begin{array}{l}\text { A little } \\
\%\end{array}$ & $\begin{array}{l}\text { Not at all } \\
\%\end{array}$ & $\begin{array}{l}\text { Importance } \\
\text { Mean }(95 \% \mathrm{CI})\end{array}$ \\
\hline Coaching colleagues & 71 & 29 & - & - & - & $4.7(4.3-5.2)$ \\
\hline Televised rugby matches & 57 & 43 & - & - & - & $4.6(4.1-5.1)$ \\
\hline Attending live rugby matches & 57 & 43 & - & - & - & $4.4(3.9-4.9)$ \\
\hline Sport/rugby shows on TV & - & 100 & - & - & - & 4.0 \\
\hline Your own playing experience & 50 & 17 & 17 & 17 & - & $4.0(2.7-5.3)$ \\
\hline Internet & 14 & 57 & 14 & 14 & - & $3.7(2.8-4.6)$ \\
\hline Rugby training videos & 14 & 43 & 29 & 14 & - & $3.6(2.7-4.5)$ \\
\hline Rugby training videos & 14 & 43 & 29 & 14 & - & $3.6(2.7-4.5)$ \\
\hline Rugby training books & - & 57 & 29 & 14 & - & $3.4(2.7-4.2)$ \\
\hline Coaching clinics & - & 29 & 71 & - & - & $3.3(2.8-3.7)$ \\
\hline Rugby magazines & - & 29 & 43 & 14 & 14 & $2.9(1.9-3.8)$ \\
\hline Attending workshops & 14 & 14 & 29 & 29 & 14 & $2.9(1.6-4.1)$ \\
\hline $\begin{array}{l}\text { Attending formal coaching/ } \\
\text { physical education courses }\end{array}$ & - & 14 & 57 & 29 & - & $2.9(2.2-3.5)$ \\
\hline Newspapers & 14 & 14 & 14 & 14 & 43 & $2.4(0.9-3.9)$ \\
\hline
\end{tabular}

Table 3. Mean ratings of importance of drills used by coaches when training the tackle for injury prevention and improving performance*

\begin{tabular}{|c|c|c|c|}
\hline \multicolumn{2}{|l|}{ Injury prevention } & \multicolumn{2}{|c|}{ Improving performance } \\
\hline Drill & Mean $(95 \% \mathrm{CI})$ & Drill & Mean $(95 \% \mathrm{CI})$ \\
\hline Giving verbal instruction & $4.57(3.84-5.3)$ & Giving verbal instruction & $4.29(3.13-5.45)$ \\
\hline Using a shield & $4.29(3.59-4.98)$ & Body armour & $4.00(2.37-5.63)$ \\
\hline Tackle bag & $3.86(2.50-5.20)$ & Using tackle bag & $3.86(2.50-5.21)$ \\
\hline Tackle drill combined with ball-skill exercise & $3.86(2.61-5.10)$ & Live tackling in a $1 \mathrm{v} .1$-player grid & $3.83(2.29-5.38)$ \\
\hline $\begin{array}{l}\text { Tackle drill combined with fitness } \\
\text { conditioning }\end{array}$ & $3.86(2.86-4.84)$ & Using a shield & $3.71(2.69-4.74)$ \\
\hline Live tackling in a $1 \mathrm{v}$. 1-player grid & $3.71(2.55-4.87)$ & $\begin{array}{l}\text { Tackle drill combined with fitness } \\
\text { conditioning }\end{array}$ & $3.71(2.83-4.59)$ \\
\hline Tackling drill combined with reaction exercise & $3.71(2.55-4.87)$ & Contact practice match & $3.71(2.69-4.74)$ \\
\hline Body armour & $3.67(2.08-5.25)$ & $\begin{array}{l}\text { Tackling drill combined with reaction } \\
\text { exercise }\end{array}$ & $3.71(2.55-4.87)$ \\
\hline Demonstration & $3.57(2.39-4.75)$ & $\begin{array}{l}\text { Tackle drill combined with ball-skill } \\
\text { exercise }\end{array}$ & $3.43(2.38-4.48)$ \\
\hline Contact practice match & $3.43(2.70-4.16)$ & Demonstration & $3.43(2.25-4.61)$ \\
\hline Tackling drill combined with vision exercise & $3.43(2.38-4.48)$ & $\begin{array}{l}\text { Tackling drill combined with vision } \\
\text { exercise }\end{array}$ & $3.29(2.26-4.31)$ \\
\hline
\end{tabular}

it either very important or important, except for one coach who indicated that he was undecided whether or not proper technique reduces the risk of injury. Interestingly, the coach who was undecided on the matter was also the most experienced coach (more than 20 years' experience) and the least qualified.
Proper techniques towards the contact phases (ball-carrying, scrumming, tackling and rucking) of the game were ranked as the most important. Almost all coaches indicated that falling to ground was important; $28 \%$ were either undecided or rated it as not too important. In a similar study on junior rugby union coaches, the most frequently 
reported phases of play that coaches perceived that they needed more technique knowledge on were scrumming, mauling, line-outs and rucking. ${ }^{[2]}$ In the same study, the least frequently reported phases of play were ball-carrier fall technique, ball-carrier contact technique, and tackling technique. ${ }^{[2]}$

Resources most often used by the coaches to increase coaching knowledge and to develop new training drills were colleagues, televised rugby matches and attendance at live rugby matches. The effect of peer interaction on implementing injury prevention programmes (correct landing technique in netball) has been highlighted recently. White et al. ${ }^{[6]}$ showed that although coaches supported the need to teach players correct landing technique, they were not sure if their colleagues were actually doing so. From this finding, it was suggested that coach education programmes should include coach role-models, as social pressure from peers may influence coaches' intentions to deliver injuryprevention programmes. ${ }^{[6]}$ Observing rugby matches (whether televised or live) as a coaching resource suggests that coaches prefer to use their own analysis of matches as a guide for setting up training. Least-often used resources for developing coaching were attending workshops, attending formal coaching/physical education courses and newspapers. In contrast, community-level junior netball coaches considered coachtraining workshops and/or coach accreditation courses to be the best way to encourage coaches to use injury-prevention programmes. ${ }^{[7]}$

Verbal instruction and the use of padded equipment (shield, bag and body armour) were ranked as the most important drills to use when training the tackle, whether to reduce the risk of injury or to improve performance. The use of padded equipment may reduce the risk of injury in training and aid the development of a player's tackle technique. ${ }^{[1]}$ With that said, it has been suggested that a more advanced player may benefit more (from an injury-prevention and performance perspective) by training in a more ecologically valid setting (e.g. live $1 \mathrm{v} .1$ tackling). ${ }^{[1,9]}$

\section{Conclusion}

Collectively, the coaches in this study demonstrated a positive attitude towards injury prevention and performance. Coaches should be informed about the phases of play with increased risk of injury, and training drills to mitigate this risk should be communicated. Ways to improve conventional modes of coach training (i.e. workshops, formal coaching courses) need further investigation, particularly with the goal of making training courses more attractive and useful for coaches. In addition, research into other means of communicating information to coaches must be emphasised (e.g. coaching role-models). ${ }^{[6]}$

Acknowledgments. The authors wish to thank the coaches who participated in the study.

Conflicts of interest. The authors have no conflicts of interest to declare.

\section{References}

1. Hendricks S, Lambert M. Tackling in rugby: Coaching strategies for effective technique and injury prevention. Int J Sport Sci Coach 2010;5(1):117-136. [http:// dx.doi.org/10.1260/1747-9541.5.1.117]

2. Carter AF, Muller R. A survey of injury knowledge and technical needs of junior Rugby Union coaches in Townsville (North Queensland). J Sci Med Sport 2008;11(2):167173. [http://dx.doi.org/10.1016/j.jsams.2007.01.004]

3. Finch C. A new framework for research leading to sports injury prevention. J Sci Med Sport 2006;9(1-2):3-9. [http://dx.doi.org/10.1016/j.jsams.2006.02.009]

4. Donaldson A, Poulos RG. Planning the diffusion of a neck-injury prevention programme among community rugby union coaches. Br J Sports Med; 2013 (in press). [http://dx.doi.org/10.1136/bjsports-2012- 091551]

5. Finch CF, White P, Twomey D, Ullah S. Implementing an exercise-training programme to prevent lower-limb injuries: Considerations for the development of a randomised controlled trial intervention delivery plan. Br J Sports Med 2011;45(10):791-796. [http://dx.doi.org/10.1136/bjsm.2010.081406]

6. White PE, Otago L, Saunders N, et al. Ensuring implementation success: How should coach injury prevention education be improved if we want coaches to deliver safety programmes during training sessions? Br J Sports Med 2013 (in press). [http://dx.doi. org/10.1136/ bjsports-2012-091987]

7. Saunders N, Otago L, Romiti M, Donaldson A, White P, Finch C. Coaches' perspectives on implementing an evidence-informed injury prevention programme in junior community netball. Br J Sports Med 2010;44(15):1128-1132. [http://dx.doi. org/10.1136/bjsm.2009.069039]

8. Twomey D, Finch C, Roediger E, Lloyd DG. Preventing lower limb injuries: Is the latest evidence being translated into the football field? J Sci Med Sport 2009;12(4):452456. [http://dx.doi.org/10.1016/j.jsams.2008.04.002]

9. Hendricks S, Jordaan E, Lambert M. Attitude and behaviour of junior rugby union players towards tackling during training and match play. Safety Sci 2012;50(2):266284. [http://dx.doi.org/10.1016/j.ssci.2011.08.061]

10. Viljoen W, Patricios J. BokSmart - implementing a National Rugby Safety Programme. Br J Sports Med 2012;46(10):692-693. [http://dx.doi.org/10.1136/ bjsports-2012-091278] 